\title{
Rectus sheath hematoma and retroperitoneal bleeding due to rivaroxaban: a case report
}

\author{
Elif Börekci
}

Department of Internal Medicine, Bozok University, School of Medicine, Yozgat, Turkey

\begin{abstract}
: Keywords: Rectus sheath hematoma, retroperitoneal bleeding, rivaroxaban.

DOI: https://dx.doi.org/10.4314/ahs.v19i2.55 2293. https://dx.doi.org/10.4314/abs.v19i2.55

\section{Introduction}

Recently, new oral anticoagulants (NOACs) have begun to be used as the alternatives of warfarin in non-valvular atrial fibrillation (AF). In general, NOACs may offer a significant advantage over warfarin for most patients. Relative to warfarin, NOACs are as effective or superior in the prevention of stroke or embolic events and unlike warfarin, do not require frequent laboratory monitoring. However, in situations requiring rapid reversal of anticoagulation such as majör bleeding, there are no specific antidotes ${ }^{1}$.
\end{abstract}

Rivaroxaban is one of the new anti-coagulants that inhibit Factor Xa and rarely cause rectus sheath hematoma and retroperitoneal haemorrhage which are uncommon, life-threatening complications. Here is a case of an elderly patient on rivaroxaban therapy for the stroke prevention in non-valvular atrial fibrillation who developed rectus sheath hematoma and retroperitoneal bleeding.

Cite as: Börekci E. Rectus sheath hematoma and retroperitoneal bleeding due to rivaroxaban: a case report. Afri Health Sci.2019;19(2): 2290-

With expanding avenues of NOACs use, the complications associated with these drugs are also increasing. NOACs are associated with a decreased risk of intracranial hemorrhage, but these agents may be associated with a slightly increased risk of gastrointestinal bleeding relative to warfarin ${ }^{2}$. Also, formation of rectus sheath hemato$\mathrm{ma}(\mathrm{RSH})$ and retroperitoneal hematoma are other such severe complications with high risk of mortality and requires a close follow up ${ }^{3}$.

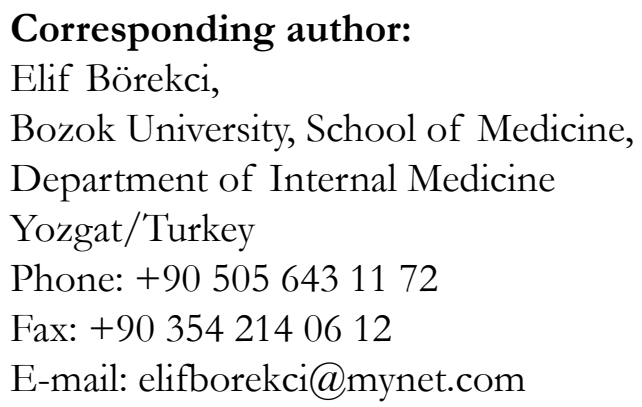

Corresponding author:

Elif Börekci,

Bozok University, School of Medicine,

Department of Internal Medicine

Yozgat/Turkey

Phone: +90 5056431172

Fax: +903542140612

E-mail: elifborekci@mynet.com

Rivaroxaban is a fast acting new oral anticoagulant that uses orally and directly inhibits Factor Xa. It is indicated for the prophylaxis and treatment of deep venous thrombosis and stroke prevention in non-valvular $\mathrm{AF}^{4,5}$. Here is a case of rivaroxaban associated RSH and minor retroperitoneal bleeding in a patient initiated on anti-coagulation for non-valvular AF.

\section{Case Report}

A 76 year old female with a history of hypertension, diabetes mellitus, hyperlipidemia, hypothyroidism, asthma and non-valvular AF presented to the emergency department with complaints of cough and acute onset severe abdominal pain in the left abdominal area with radiation to the back. On physical examination; she had wide ecchymotic area on anterior abdominal wall extending to the left lumbar region and widespread tenderness and voluntary defenses were present. There was no rebound tenderness Figure 1. Her blood pressure was 128/70 mm $\mathrm{Hg}$, pulse 98 beats/minute, respiratory rate 18 breaths/ minute, and temperature $36.7^{\circ} \mathrm{C}$. Laboratory studies showed normal white blood cell count, hemoglobin of $9.5 \mathrm{~g} / \mathrm{dL}$ normal range $12-18.1 \mathrm{~g} / \mathrm{dl}$, hematocrit of $32.1 \%$ normal range $36 \%-53.7 \%$, platelets of $296 \times 10^{3} / \mathrm{mm}^{3}$ normal range $140-400 \times 10^{3} / \mathrm{mm}^{3}$, normal international normalized ratio, blood urea nitrogen of $39 \mathrm{mg} / \mathrm{dL}$ normal range $5-22 \mathrm{mg} / \mathrm{dL}$, and normal creatinine. The computed tomography of the abdomen with contrast showed left $\mathrm{RSH}$ measuring approximately $10 \times 4 \times 12 \mathrm{~cm}$ and minimal hemorrhagic areas in the retroperitoneum Figure 2.

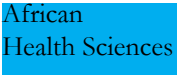

(C) 2019 Börekci E. Licensee African Health Sciences. This is an Open Access article distributed under the terms of the Creative commons Attribution License (https://creativecommons.org/licenses/BY/4.0), which permits unrestricted use, distribution, and reproduction in any medium, provided the original work is properly cited. 


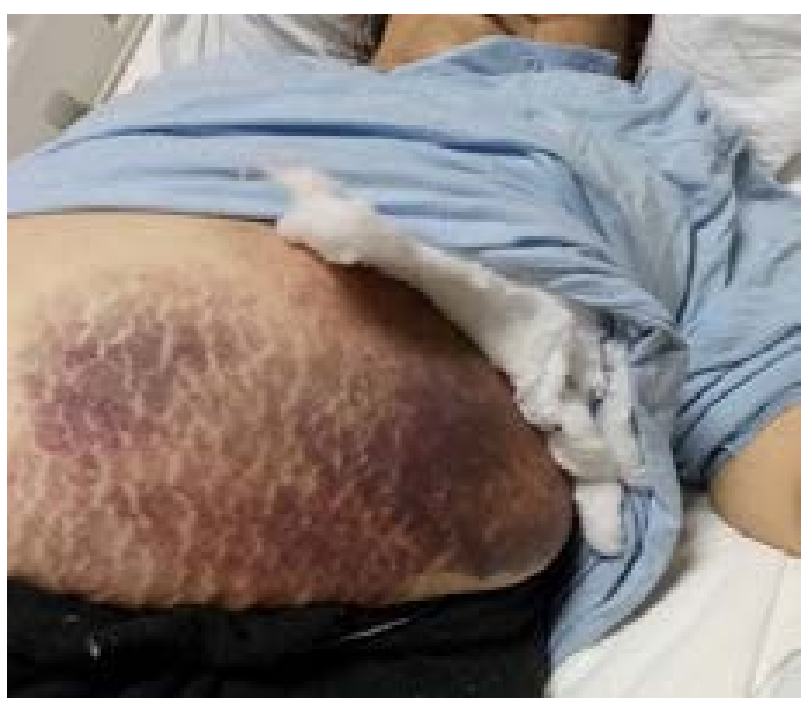

Wide ecchymotic area on anterior abdominal wall extending to the left lumbar region.

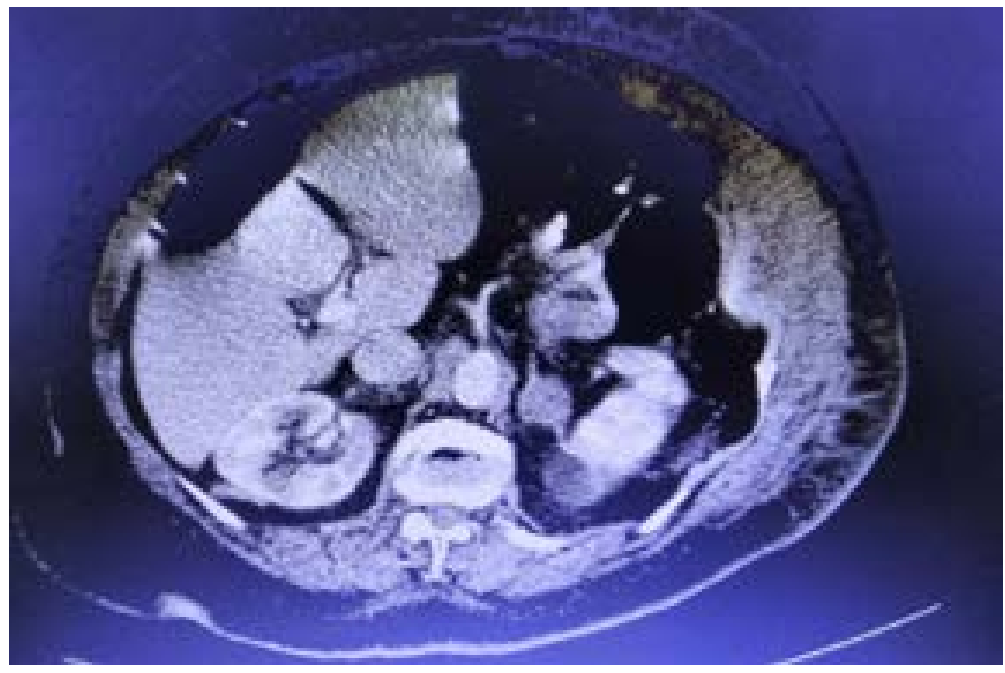

Contrast CT scan image of abdomen. Image shows left rectus sheath hematoma and minor retroperitoneal bleeding area.

As part of a treatment for her non-valvular AF, the patient had been using rivaroxaban at a dose of $15 \mathrm{mg} /$ day for the past three months. She had no history of trauma and had not used any other drug that could account for the bleeding and hematoma formation. Her daily drugs were as follows: diltiazem $90 \mathrm{mg} /$ day $\mathrm{mg}$, furosemide 40 $\mathrm{mg} /$ day, rivaroxaban $15 \mathrm{mg} /$ day, metformin $2 \mathrm{gr} /$ day, levothyroxine sodium $100 \mu \mathrm{g} /$ day, budesonide/formoterol $400 \mu \mathrm{g} / 12 \mu \mathrm{g}$ twice a day and salbutamol as needed.
Rivaroxaban was discontinued and the patient was monitored for extension of the hematoma. Two units of packed red blood cells and fresh frozen plasma were administered. She remained hemodynamically stable and hemoglobin values were regularly controlled and showed no significant decrease. After 7 days, she was discharged home with dabigatran at the dose of $110 \mathrm{mg}$ twice a day instead of rivaroxaban.

At her follow-up visit 1 week later, complaints and 
symptom of hematoma were regressed and her blood counts remained stable.

\section{Discussion}

AHA guidelines recommend warfarin evidence level I-A, dabigatran evidence level I-B,rivaroxaban evidence level IIa-B, and apixaban evidence level I-A as preferred agents to prevent the risk of thromboembolism in $\mathrm{AF}^{6,4}$. Nevertheless, rarely, these drugs can lead to serious haemorrhagic complications. RSH and retroperitoneal haemorrhage are rare but important complications of anticoagulant therapy and there have been rare reported cases developing hemorrhage while receiving rivaroxaban ${ }^{7,8,9}$

Although RSH is rare, there is a well-defined pathogenesis, clinic and treatment ${ }^{3}$. There are superior and inferior epigastric venules along the posterior border of the rectus sheath, Rupture of these vessels or rupture of the rectus abdominis results in $\mathrm{RSH}^{9}$. Spontaneous sheath hematomas may occur in elderly humans as the elasticity of the epigastric veins decreases due to atheromatous wall changes ${ }^{10}$. Possible risk factors include trauma, rapid and sudden position changes, anticoagulation therapy, new history surgical operation, acute exacerbation of asthma-chronic obstructive pulmonary disease with cough attacks, injections and pregnancy ${ }^{11}$. Rectus sheath hematomas are often self-limited, so treatment is conservative. But, surgical treatment is indicated in hematomas that cause hemodynamic disorders and complicated hematomas peritoneal rupture, infection, etc. ${ }^{13}$.

There is no clear antidote to reverse the effects of rivaroxaban. The average terminal half-life of rivaroxaban is 7-11 hours, so conservative treatment for bleeding events will be effective for the majority of patients ${ }^{7}$. Such hematoma treatment involves regular monitoring of hemoglobin levels and, if necessary, supportive treatment based on erythrocyte transfusion. Many studies have shown that prothrombin complex concentration may be useful in reversing the effects of rivaroxaban. Another option would be to use recombinant Factor VIIa to reduce bleeding ${ }^{14}$.

It is essential to choose the appropriate patients for treatment with NOACs to reduce the risk of adverse events. Also, the most important point in terms of clinicians is appropriate dose selection in patients for new generation agents; because there is not yet an antidote that can be used when there is major bleeding due to the use of the new generation oral anticoagulant ${ }^{15}$. For Rivaroxaban; patients with moderate to severe renal impairment (creatinine clearence) $\mathrm{CrCl} 15-49$, a dose adjustment to $15 \mathrm{mg}$ once daily is recommended, but dose adjustment forbody weight or elderly age is not recommended ${ }^{15}$.

We recommend that clinicians choose the appropriate patients, select appropriate dose and become aware of the potential for rare and serious bleeding complications of anticoagulants and identify the need for early recognition and prompt management.

\section{Conflict of interest}

None declared.

\section{References}

1. Ntaios G, Papavasileiou V, Diener HC, Makaritsis K, Michel P. Nonvitamin-K antagonist oral anticoagulants in patients with atrial fibrillation and previous stroke or transient ischemic attack: a systematic review and meta-analysis of randomized controlled trials. Stroke. 2012;4312:3298-304

2. Ruff CT, Giugliano RP, Braunwald E, Hoffman EB, Deenadayalu N, Ezekowitz MD, et al. Comparison of the efficacy and safety of new oral anticoagulants with warfarin in patients with atrial fibrillation: a meta-analysis of randomised trials. Lancet. 2014 Mar 15; 3839921:955-62 3. Linhares MM, Lopes Filho GJ, Bruna PC, Ricca NY, Sato NY, Sacalabrini M. Spontaneous hematoma of the rectus abdominis sheath: a review of 177 cases with report of 7 personal cases. Int Surg. 1999;84: 251-7. PubMed 4. Furie KL, Goldstein LB, Albers GW, Khatri P, Neyens R, Turakhia MP, et al. Oral Antithrombotic Agents for the Prevention of Stroke in Nonvalvular Atrial Fibrillation: A Science Advisory for Healthcare Professionals From the American Heart Association/American Stroke Association. Stroke. 2012;4312:3442-53. PubMed

5. Patel M.R, Mahaffey K.W, Garg J, Pan G, Singer DE, Hacke W, et al. Rivaroxaban versus warfarin in nonvalvular atrial fibrillation. N Engl J Med. 2011;36510:883-91. PubMed

6. Wann LS, Curtis AB, Ellenbogen KA, Estes NA 3rd, Ezekowitz MD, Jackman WM, et al. 2011 ACCF/AHA/ HRS focused update on the management of patients with atrial fibrillation update on dabigatran: a report of the American College of Cardiology Foundation/American Heart Association Task Force on practice guidelines. Journal of the American College of Cardiology. 2011;5711:1330-7

7. Kocayigit I, Can Y, Sahinkus S, Ercan Aydin, Meh- 
met Bulent Vatan, Harun Kilıc, et al. Spontaneous rectus sheath hematoma during rivaroxaban therapy. Indian J Pharmacol. 2014 May-Jun; 463: 339-40.

$\mathrm{f}$ rivaroxaban and dabigatran by prothrombin complex concentrate: a randomized, placebo-controlled, crossover study in

8.Talari G, Talari P, Sweigart J, Ahmed S. Rare case of losartan-induced cough complicated by rectus sheath haematoma: in a patient on rivaroxaban therapy. BMJ Case Rep. 2016 Dec 23;2016. pii: bcr2016217801. doi: 10.1136/ bcr-2016-217801

9. Deekonda P, Stokes OM, Chan D. Retroperitoneal haematoma in a postoperative ALIF patient taking rivaroxaban for atrial fibrillation. Eur Spine J. 2016 Nov 2. [Epub ahead of print]

10. Henzel JH, Pories WJ, Smith JL, Burget DE, Plecha
FR. Pathogenesis and management of abdominal wall hematomas. Arch Surg. 1966;93: 929-35. PubMed 11. Verhagen HJM, Tolenaar PL, Sybrandy R. Hematoma of the rectus abdominis muscle. Eur J Surg. 1993;159:33538. PubMed

12. Cherry WB, Mueller PS. Rectus sheath hematoma: review of 126 cases at a single institution. Medicine Baltimore. 2006 Mar; 852:105-10.

13. Berna JD, Zuazu I, Madrigal M, Garcia-Medina V, Fernandez C, Guarido F. Conservative treatment of large rectus sheath hematoma in patients undergoing anticoagulant therapy. Abdom Imaging. 2000;25: 230-4. PubMed 14. Eerenberg ES, Kamphuisen PW, Sijpkens MK, Meijers JC, Buller HR, Levi M. Reversal o healthy subjects. Circulation. 2011 Oct 4; 12414:1573-9

15. Alings M. Individualising Anticoagulant Therapy in Atrial Fibrillation Patients. Arrbythm Electrophysiol Rev. 2016 Aug; 52: 102-9 